\title{
Investigation of antibiotics in mollusks from coastal waters in the Bohai Sea of China
}

\author{
Wenhui $\mathrm{Li}^{\mathrm{a}}$, Yali Shi ${ }^{\mathrm{a}}$, Lihong Gao ${ }^{\mathrm{b}}$, Jiemin Liu ${ }^{\mathrm{b}}$, Yaqi Cai ${ }^{\mathrm{a}, *}$ \\ a State Key Laboratory of Environmental Chemistry and Ecotoxicology, Research Center for Eco-Environmental Science, Chinese Academy of Sciences, Beijing 100085, China \\ ${ }^{\mathrm{b}}$ Civil and Environment Engineering School, University of Science and Technology Beijing, Beijing 100083, China
}

\section{A R T I C L E I N F O}

\section{Article history:}

Received 21 June 2011

Received in revised form

12 October 2011

Accepted 18 October 2011

\section{Keywords:}

Antibiotics

Quinolones

Sulfonamides

Macrolides

Mollusks

\begin{abstract}
A B S T R A C T
This study focused on the presence and distribution of 22 antibiotics, including eight quinolones, nine sulfonamides and five macrolides in mollusks from the Bohai Sea of China. 190 samples of eleven species were collected in 2006, 2007 and 2009. Laboratory analyses revealed that antibiotics were widely distributed in the mollusks with quinolones as the major compounds with concentrations of $0.71 \sim 1575.10 \mu \mathrm{g} / \mathrm{kg}$, which were up to two orders of magnitude higher than those of sulfonamides $(0 \sim 76.75 \mu \mathrm{g} / \mathrm{kg})$ and macrolides $(0 \sim 36.21 \mu \mathrm{g} / \mathrm{kg})$. The contents of quinolones and macrolides did not show significant changes from 2006, 2007 to 2009, while sulfonamides decreased significantly from 2006 to 2009. Compared with other sites, the city of Dalian was more polluted with quinolones, while Beidaihe was more contaminated with erythromycin and sulfapyridine. In addition, Mactra veneriformis and Meretrix merehjgntrix Linnaeus contained higher concentrations of quinolones and sulfamonomethoxine, while Mytilus edulis had higher levels of erythromycin and sulfapyridine.
\end{abstract}

(c) 2011 Elsevier Ltd. All rights reserved.

\section{Introduction}

Antibiotics are widely used to treat infectious diseases for both humans and animals (Kümmerer, 2009). Some antibiotics are also used in livestock farming, aquaculture and agriculture (Cruz Moreno-Bondi et al., 2009). However, many antibiotics cannot be completely metabolized in the body, and the excreted portion cannot be eliminated by the sewage treatment plants. In addition, direct disposal of medical and industrial wastes also contain antibiotics. Therefore, the water cycle is contaminated with a large amount of antibiotics (Massey et al., 2010). They persist in the environment, because most of them are replaced by ongoing wide use, although they are being degraded at a certain rate (Cunningham et al., 2009).

Antibiotic contamination has attracted increasing attention due to its undesirable effects on ecosystems and the health of humans and animals (Sapkota et al., 2008; Wang, 2009; Ye et al., 2007). Most studies have focused on the antibiotics that may cause resistance among natural bacterial populations. In recent years, more and more attention was paid to the antibiotic resistance genes (ARGs), which have been recognized as a new emerging contaminant in environment (Luo et al., 2010; Zou et al., 2011). It has been shown that not only this resistance can be transmitted to the

\footnotetext{
* Corresponding author.

E-mail address: caiyaqi@rcees.ac.cn (Y. Cai).
}

general population that facilitates antibiotic-resistant infections, but also antibiotic-resistant bacteria can pass through the food chain from animals to humans (Canada-Canada et al., 2009; DíazCruz et al., 2009; Sapkota et al., 2008).

As the most common antibiotics, quinolones (QNs), sulfonamides (SAs) and macrolides (MCs) have been found in different environmental compartments, such as water (Ternes et al., 2007), sewage sludge (Golet et al., 2002), sediments (Arikan et al., 2008), and soils (Hu et al., 2010; Tamtam et al., 2011), and in foods (Nie et al., 2009) and animals (Juan-Garcia et al., 2007). An increasing number of analytical methods have been developed for animals and foods, while only very limited information is available for the occurrence and fate of antibiotics, especially for marine system such as gulf, bay or sea, where many pollutants have been concerned to a great extent due to their transfers to open sea (Zhang et al., 2009).

Bohai Bay is the biggest semi-enclosed sea located in the northeast of China and the Bohai Bay Economic Rim surrounding Bohai Sea is an important economic center that possesses about $17 \%$ of the total population and contributes about $25 \%$ of total GDP of China (Wang et al., 2008). Rapid economic development has been associated with serious environmental pollutions problems. Many pollutants have been proved to be widespread in Bohai Bay in the previous study (Liang et al., 2003; Wang et al., 2007). However, research on antibiotic pollution in Bohai Bay area has been very limited (Na et al., 2009; Zou et al., 2011). 
Recently, several studies have used mollusks as potential biomonitors because of their high accumulation capacity and high abundance in marine ecosystems (Pan et al., 2010; Yang et al., 2008). Therefore, we used mollusks in this study to investigate the distribution of quinolones, sulfonamides, and macrolides from nine typical coastal sites along the Chinese Bohai Sea. This study is the first to demonstrate the ubiquitous occurrence of three major types of antibiotics in a large water system.

\section{Materials and methods}

\subsection{Regents}

HPLC-grade methanol and acetonitrile were purchased from Fisher Scientific (Pittsburgh, PA, USA); Ammonium formate (99\%) and ammonium hydroxide (V/V $50 \%$ ) were purchased from Alfa Aesar (USA); Formic acid (98\%) was purchased from Fluka (USA). All purity water $\left(>18.2 \mathrm{M} \Omega \mathrm{cm}^{-1}\right)$ was prepared with Milli-Q Advantage A10 system (Millipore, USA).

Ofloxacin (OFL, 99.9\%), norfloxacin (NOR, 99.9\%), ciprofloxacin (CIP, 99.9\%), sarafloxacin (SAR, 95.0\%), fleroxacin (FLE, 99.5\%), lomefloxacin (LOM, 98.0\%), difloxacin (DIF, 98.0\%), enrofloxacin (ENR, 99.9\%), sulfadiazine (SDZ, 99.7\%), sulfamerazine (SMR, 99.9\%), sulfadimethoxine (SDM, 99.4\%), sulfisoxazole (SIA, 99.0\%), sulfamonomethoxine (SMM, 99.0\%), erythromycin (ERY, 99.1\%), roxithromycin (ROX, 90.0\%), josamycin (JOS, 98.0\%), tylosin (TYL, 82.4\%), and spiramycin (SPI, 88.9\%) were purchased from Sigma-Aldrich (St. Louis, MO, USA). Sulfathiazole (ST, 99.0\%), sulfapyridine (SPD, 99.0\%), sulfamethoxazole (SMX, 99.0\%), and sulfamethazine (SDMD, 99.0\%) were purchased from KaSei Industry Co., Ltd. (Tokyo, Japan).

The following isotopically labeled compounds were used as surrogates standards $\left(100.0 \mu \mathrm{g} / \mathrm{L}\right.$ in methanol): norfloxacin- $\mathrm{d}_{5}\left(\mathrm{NOR}-\mathrm{d}_{5}\right)$, ofloxacin- $\mathrm{d}_{3}\left(\right.$ OFL- $\left.\mathrm{d}_{3}\right)$ and sarafloxacin- $\mathrm{d}_{8}\left(\mathrm{SAR}-\mathrm{d}_{8}\right.$ ) that were purchased from Sigma-Aldrich (St. Louis, MO, USA); and sulfamethoxazole- $\mathrm{d}_{4}\left(\mathrm{SMX}-\mathrm{d}_{4}\right)$, sulfamethazine- $\mathrm{d}_{4}\left(\mathrm{SDMD}-\mathrm{d}_{4}\right)$, spiramycin $\mathrm{I}-\mathrm{d}_{3}\left(\mathrm{SPI} I-\mathrm{d}_{3}\right)$, and erythromycin- ${ }^{13} \mathrm{C}, \mathrm{d}_{3}\left(\right.$ ERY- $\left.{ }^{13} \mathrm{C}, \mathrm{d}_{4}\right)$ that were purchased from Toronto Research Chemicals (Oakville, ON, Canada).

\subsection{Sample collection}

The samples were collected three times in late July to early August of 2006 2007 and 2009. A total of 190 pooled mollusk samples were collected from nine coastal cities along the Bohai Sea, including Dalian, Yingkou, Huludao, Beidaihe, Tianjin, Shouguang, Penglai, Yantai and Weihai (Fig. 1). Most of the sampling sites were large and busy seaports with a large population. The population in the selected cities was shown in Table S1. Eleven species of mollusks that are commercial seafoods were selected, including Crassostera talienwhanensis (Cra), Chlamys farreri (Chl), Amussium (Amu), Scapharca subcrenata (Sca), Meretrix merehjgntrix Linnaeus (Mer), Mactra veneriformis (Mac V), Mactra chinesis (Mac C), Mya arenaria (Mya), Neverita didyma (Nev), Rapana venosa (Rap), and Mytilus edulis (Myt) (Table S2).

All mollusk samples were always kept at low temperature after collection. They were unshelled in the laboratory, and tissue homogenate was lyophilized and ground into fine powders before analyzed. All samples were stored at $-20{ }^{\circ} \mathrm{C}$ until chemical analysis.

\subsection{Sample preparation}

Chemical analysis was following the EPA method 1694 developed by the US Environmental Protection Agency (EPA) (EPA, 2007) with some modifications. The twenty-two target compounds in mollusc samples, including eight quinolones, nine sulfonamides, and five macrolides, were simultaneously extracted using an ASE 350 pressurized liquid extraction (PLE) system (Dionex, Sunnyvale, CA, USA). $0.1 \mathrm{~g}$ of pretreated lyophilized mollusc sample was spiked with $20 \mathrm{ng}$ of internal standard (Norfloxacin- $\mathrm{d}_{5}$, Ofloxacin- $\mathrm{d}_{3}$, Sarafloxacin- $\mathrm{d}_{8}$, Sulfamethoxazole- $\mathrm{d}_{4}$, Sulfamethazine- $\mathrm{d}_{4}$, Spiramycin $\mathrm{I}-\mathrm{d}_{3}$ and Erythromycin- ${ }^{13} \mathrm{C}_{3}$ ) before being thoroughly mixed with $7 \mathrm{~g}$ of diatomite from Varian (Walnut Creek, KS, USA). The mixture was put into a $34 \mathrm{~mL}$ stainless steel extraction cell with $100 \%$ methanol as the extracting solvent.

The extraction conditions were: extraction temperature, $70{ }^{\circ} \mathrm{C}$; extraction pressure, $1500 \mathrm{psi}$; preheating period, $5 \mathrm{~min}$; static extraction, $10 \mathrm{~min}$; final extraction volume, $60 \mathrm{~mL}$; flush volume $60 \%$ of the cell volume; nitrogen purge, $120 \mathrm{~s}$; and number of extraction cycles, 2. Each PLE extract was concentrated by RE2000 rotary evaporator (Yarong, Shanghai, China) to a final volume of about $1 \mathrm{~mL}$ at $37^{\circ} \mathrm{C}$ and $0.08 \mathrm{MPa}$ in $100 \mathrm{~mL}$ round-bottom flasks. Immediately after concentration, the extract was transferred to a $100 \mathrm{~mL}$ conical tube and the round-bottom flasks was rinsed twice with $0.5 \mathrm{~mL}$ of methanol, and then add $100 \mathrm{~mL}$ of regent water to this conical tube.

Solid-phase extraction was performed on $6 \mathrm{~mL}$ Oasis HLB sorbent cartridges (200 mg; Waters) that were pre-conditioned with $5 \mathrm{~mL}$ methanol and $5 \mathrm{~mL}$ water at a flow rate of $1 \mathrm{~mL} / \mathrm{min}$. After they passed through the cartridges, the samples were washed with $10 \mathrm{~mL}$ of water and vacuum-dried for $30 \mathrm{~min}$. Analytes were eluted with $6 \mathrm{~mL}$ methanol containing $5 \%(\mathrm{v} / \mathrm{v})$ ammonia into $15 \mathrm{~mL}$ conical tube flask. The eluate was collected and concentrated to $1 \mathrm{~mL}$ under a gentle stream of nitrogen before being dissolved with $1 \mathrm{~mL}$ of a mixture of methanol/aqueous solution of formic acid, $0.05 \%(10: 90 \mathrm{v} / \mathrm{v})$. Then the extract was centrifuged for $5 \mathrm{~min}$ at $12,000 \mathrm{rpm}$. Finally, the supernatant was filtered through a $0.22 \mu \mathrm{m}$ nylon filter, and an aliquot $(15 \mu \mathrm{L})$ of it was injected for liquid chromatography/tandem mass spectrometry.

\subsection{Liquid chromatography/tandem mass spectrometry}

The LC-MS/MS system consisted of an Ultimate 3000 HPLC (Dionex, Sunnyvale, CA, USA) and a triple-quadrupole mass spectrometer (API 3200; Applied Biosystems/MDS SCIEX, US) with electrospray ionization (ESI). XTerra MS C18 column $(3 \mu \mathrm{m}, 100 \mathrm{~mm} \times 2 \mathrm{~mm}$ ) was used as the analytical column at a flow rate of $0.20 \mathrm{~mL} /$ min. Methanol-acetonitrile $(1: 1, \mathrm{~V} / \mathrm{V})$ were used as mobile phase $\mathrm{A}$, and $0.3 \%$ formic acid/water (containing $0.1 \%$ ammonium formate, $\mathrm{V} / \mathrm{V}, \mathrm{pH}=2.9$ ) was used as mobile phase $B$. The gradient program was as follows: the mobile phase starting conditions were $10 \%$ of $A$ for $2.0 \mathrm{~min}$, and $A$ was increased to $70 \%$ in $10.0 \mathrm{~min}$ before being increased to $100 \%$ in $4.0 \mathrm{~min}$; $100 \%$ of $\mathrm{A}$ for $3.0 \mathrm{~min}$, followed by returning to the initial composition in $0.1 \mathrm{~min}$, which was maintained for $13.9 \mathrm{~min}$. The total run time was 33.0 min.

For the MS detection, the instrument was operated in the positive electrospray ionization and multiple reactions monitoring (MRM) mode. The MS/MS parameters are as follows: curtain gas pressure, $0.14 \mathrm{MPa}$; Collision gas pressure, $0.02 \mathrm{MPa}$; ion spray voltage, $5000 \mathrm{~V}$; Temperature, $600{ }^{\circ} \mathrm{C}$; Gas1, $0.38 \mathrm{MPa}$; and Gas2, $0.45 \mathrm{MPa}$. Other parameters of $\mathrm{MS} / \mathrm{MS}$ and ion pair are listed in Table S3.

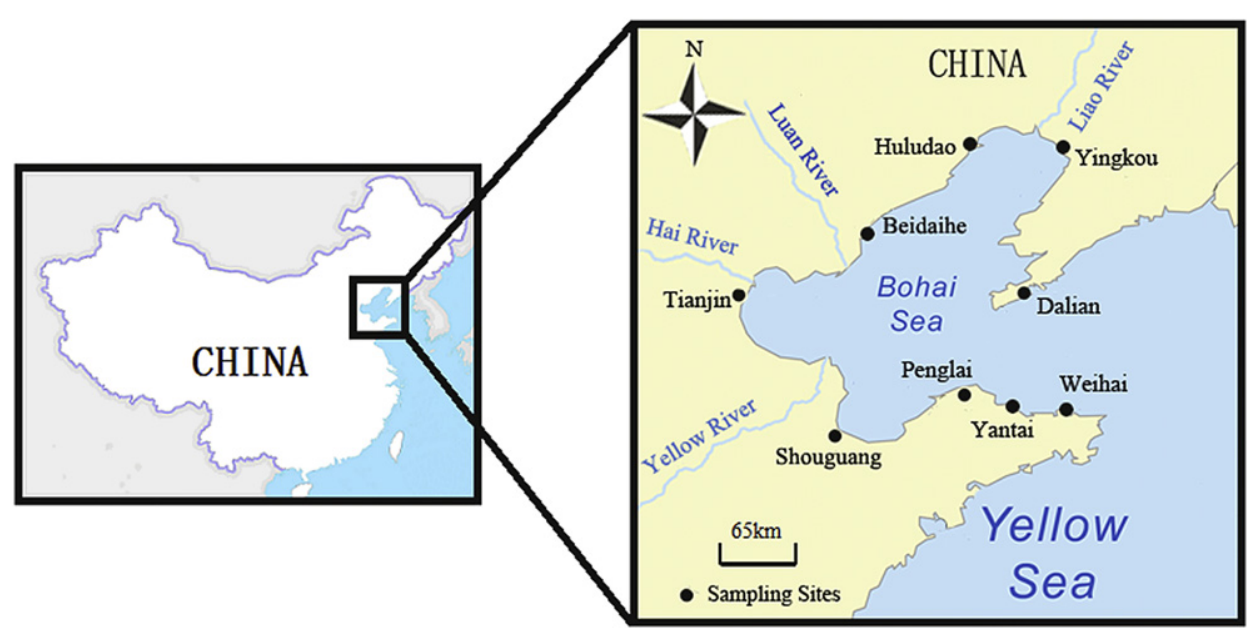

Fig. 1. Sampling locations of mollusk samples along the Bohai Sea in China. 


\subsection{Quality assurance and quality control}

The concentrations were determined by an internal standard method. Ten concentration points $[0.01,0.05,0.1,0.5,1,5,10,50,100$, and $500 \mu \mathrm{g} / \mathrm{L}$ in water- methanol (9:1, v: v)] of individual antibiotics were used as standards, and the linearity of calibration curves was confirmed $\left(r^{2}>0.99\right)$.

The degradation loss during storage was determined as not significant $(<20 \%)$ by measuring the antibiotic concentrations before and after one month's storage in the dark at $-20{ }^{\circ} \mathrm{C}$. Field blanks and procedural blanks were analyzed with extraction to control travel contamination and laboratory contamination, and all equipments and containers were rinsed with methanol and water before use to avoid analytical interference and/or cross contamination.

The limits of detection (LODs) and limits of quantification (LOQs) are listed in Table S4. LODs and LOQs were determined as the amounts for which signal-to-noise ratios $(\mathrm{S} / \mathrm{N})$ were higher than 3 and 10 , respectively. A $10 \mu \mathrm{g} / \mathrm{L}$ standard was set as the quality control concentration, which was checked every 10 injections to ensure analysis stability and to verify calibration. The calibration curve was used for quantification only when the quality control standard was within $20 \%$ of its initial value.

\subsection{Statistical analysis}

All statistical analyses were performed with IBM PASW Statistics 18.0 (SPSS Inc., 1993-2007). One-way analysis of variance (ANOVA) and principal component analysis (PCA) were used to visualize the relationships among the antibiotic concentrations in the experimented mollusks. It was considered as statistically significant difference when $p<0.05$ for ANOVA. For PCA, principal factors should account for approximately $75 \%$ of the total variance, and the principal components (PCs) were extracted for eigen values that were greater than 1 (Wiechula et al., 2006).

\section{Results and discussion}

\subsection{Antibiotics in mollusks}

The dry-weight-based concentrations of 22 antibiotics, including quinolones, sulfonamides and macrolides, are listed in
Table S5. All target antibiotics except tylosin were detected in the 190 mollusks samples. QNs were the most concentrated, with a mean $\sum$ QNs concentration of $86.76 \mu \mathrm{g} / \mathrm{kg}$. The levels of SAs and MCs were lower than QNs', with mean concentrations of 5.99 and $2.58 \mu \mathrm{g} / \mathrm{kg}$, respectively. The concentrations of individual QNs, SAs and MCs are illustrated by box-and-whisker plots in Fig. 2b, $\mathrm{c}$ and d, respectively. NOR, CIP, FLE, OFL and SAR were the predominant antibiotics, with higher than $10.00 \mu \mathrm{g} / \mathrm{kg}$ of mean concentrations and high detection frequencies (>75\%). As a contrast, SDZ, SDM, SDMD, JOS and ROX had lower than $0.20 \mu \mathrm{g} / \mathrm{kg}$ of mean concentrations and low detection frequencies $(<40 \%)$.

\subsubsection{QNs}

The prominent antibiotics in the mollusks were QNs. The concentration of $\sum$ QNs ranged from 8.79 (Mer, Yantai) to $557.00 \mu \mathrm{g} / \mathrm{kg}$ (Sca, Yantai) in the 2006 samples, from 0.71 (Amu, Weihai) to $1575.10 \mu \mathrm{g} / \mathrm{kg}$ (Mer, Dalian) in the 2007 samples, and from 3.93 (Rap, Yingkou) to $398.00 \mu \mathrm{g} / \mathrm{kg}$ (Mac C, Weihai) in the 2009 samples, respectively. The detection rate of eight quinolones ranged from 56 to $87 \%$, indicating extensive quinolones pollution along the Bohai coast (Table 1). Compared with SAs and MCs, quinolones were strongly adsorbed into sewage sludge and sediments without biodegradation, which promotes their persistence in the environment (Cruz Moreno-Bondi et al., 2009). In addition, quinolones were stable in edible animal tissues (Juan-Garcia et al., 2006).

The mean concentrations of QNs in the mollusks were in the order of "NOR $>$ OFL $>$ CIP $>$ FLE $>$ SAR $>$ LOM $>$ ENR $>$ DIF". The concentrations of NOR ranged from below detection limit (BDL) to $370 \mu \mathrm{g} / \mathrm{kg}$ (mean $18.82 \mu \mathrm{g} / \mathrm{kg}$ ), followed by those of OFL (BDL to $242 \mu \mathrm{g} / \mathrm{kg}$, mean: $14.65 \mu \mathrm{g} / \mathrm{kg}$ ), CIP (BDL to $208 \mu \mathrm{g} / \mathrm{kg}$, mean:
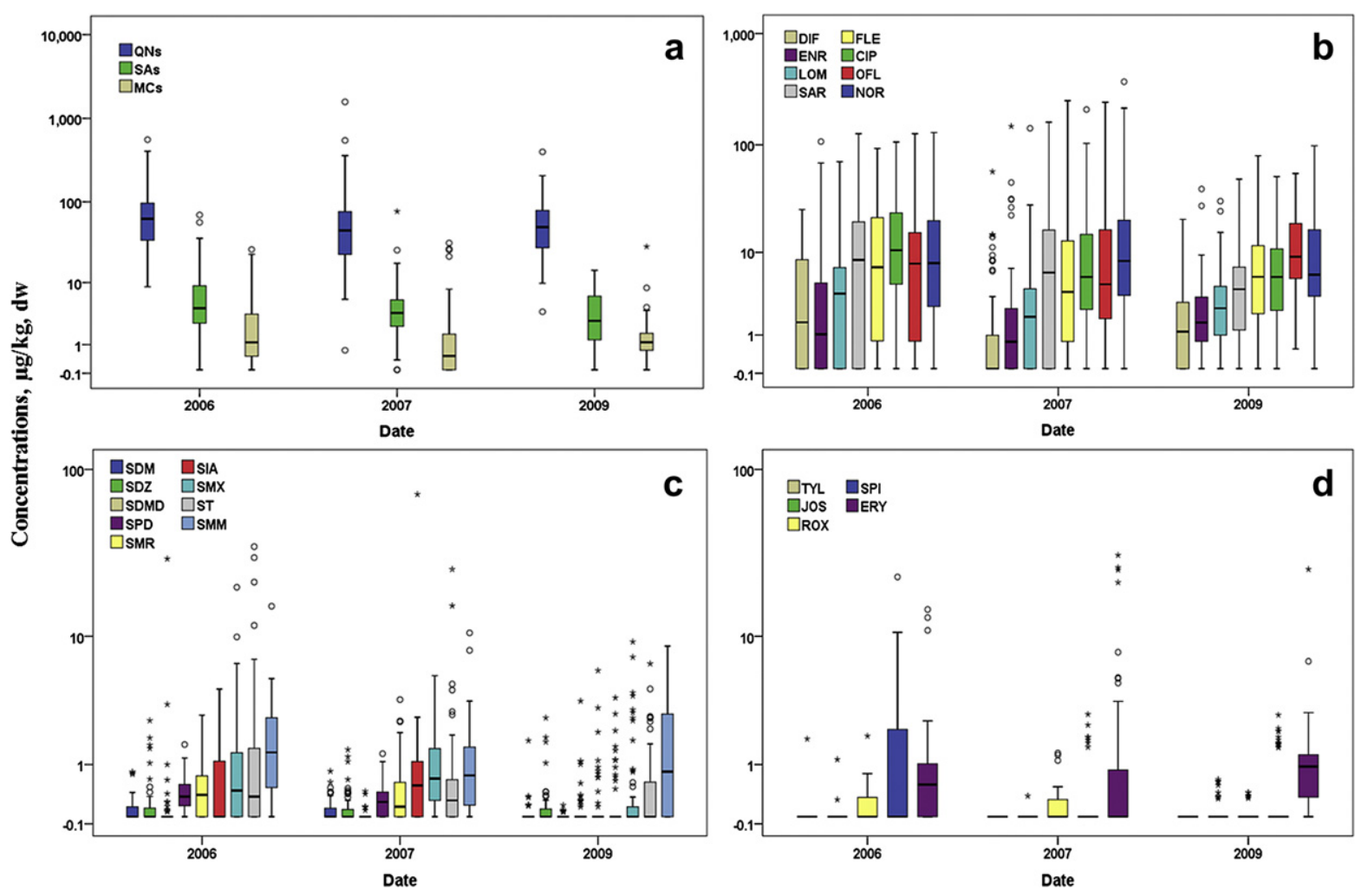

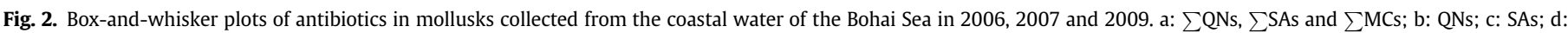

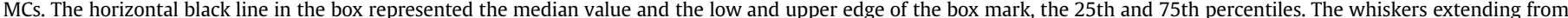

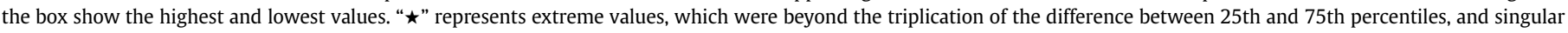
values are represented by "O", which were beyond the 150th percentile of the difference between 25 th and 75th percentiles. 
Table 1

Concentrations of QNs, SAs and MCs in mollusks from the Bohai Sea $(\mu \mathrm{g} / \mathrm{kg}, \mathrm{dw})$.

\begin{tabular}{lrllrl}
\hline Analyte & Mean & Median & Minimum & Maximum & Detectable (\%) \\
\hline NOR & 18.82 & 7.70 & 0.00 & 370.00 & 87 \\
CIP & 14.54 & 7.17 & 0.00 & 208.00 & 85 \\
DIF & 3.14 & 0.83 & 0.00 & 57.10 & 56 \\
ENR & 5.43 & 1.14 & 0.00 & 147.00 & 62 \\
FLE & 13.57 & 5.58 & 0.00 & 250.00 & 81 \\
OFL & 14.65 & 7.03 & 0.00 & 242.00 & 87 \\
LOM & 5.67 & 2.54 & 0.00 & 141.00 & 76 \\
SAR & 10.94 & 5.54 & 0.00 & 160.00 & 75 \\
ST & 1.33 & 0.17 & 0.00 & 35.20 & 51 \\
SMX & 1.01 & 0.37 & 0.00 & 20.10 & 57 \\
SIA & 0.91 & 0.00 & 0.00 & 71.60 & 47 \\
SDZ & 0.16 & 0.00 & 0.00 & 2.72 & 29 \\
SPD & 0.26 & 0.18 & 0.00 & 3.65 & 61 \\
SDM & 0.08 & 0.00 & 0.00 & 1.75 & 31 \\
SDMD & 0.20 & 0.00 & 0.00 & 29.80 & 13 \\
SMR & 0.42 & 0.00 & 0.00 & 5.98 & 45 \\
SMM & 1.60 & 1.02 & 0.00 & 15.40 & 77 \\
SPI & 0.78 & 0.00 & 0.00 & 23.20 & 22 \\
JOS & 0.03 & 0.00 & 0.00 & 1.14 & 7 \\
TYL & 0.01 & 0.00 & 0.00 & 1.81 & 1 \\
ERY & 1.65 & 0.54 & 0.00 & 31.30 & 65 \\
ROX & 0.11 & 0.00 & 0.00 & 1.92 & 24 \\
\hline & & & & &
\end{tabular}

$14.54 \mu \mathrm{g} / \mathrm{kg}$ ), FLE (BDL to $250 \mu \mathrm{g} / \mathrm{kg}$, mean: $13.57 \mu \mathrm{g} / \mathrm{kg}$ ), and SAR (BDL to $160 \mu \mathrm{g} / \mathrm{kg}$, mean: $10.94 \mu \mathrm{g} / \mathrm{kg}$. The last three QNs, LOM, ENR, and DIF, were frequently detected but with low mean concentrations below $6.00 \mu \mathrm{g} / \mathrm{kg}$.

QNs were rarely analyzed in mollusks around the world, while some data in other seafood species were available (Juan-Garcia et al., 2007; Zhao et al., 2007). NOR, OFL, CIP and ENR were often detected in fish samples. For example, NOR was found to be the main contaminant of Anguilla japonica tissues with a concentration of $2.0-100.54 \mu \mathrm{g} / \mathrm{kg}$ in fish from the Pearl River Delta, China (Nie et al., 2009), which is consistent with the present study. The high concentration of NOR is probably caused by its over-consumption in China, partially due to its low price. Xie et al. (2008) reported lower concentrations of OFL (1.5-7.4 $\mu \mathrm{g} / \mathrm{kg})$, CIP (7.6-31.6 $\mu \mathrm{g} / \mathrm{kg})$, and ENR $(3.9-13.5 \mu \mathrm{g} / \mathrm{kg})$ in roast eels in China. Compared with other foodstuffs, the concentrations of QNs in mollusks from the Bohai Sea were slightly high. Zhao et al. (2007) reported lower concentration of NOR $(5.6-12.5 \mu \mathrm{g} / \mathrm{kg})$, CIP $(1.5-59.3 \mu \mathrm{g} / \mathrm{kg})$ and ENR $(17.3-85.3 \mu \mathrm{g} / \mathrm{kg})$ in chicken muscle tissues in China, and similar concentration of NOR $(1.1-43.2 \mu \mathrm{g} / \mathrm{kg})$, CIP $(1.0-73.6 \mu \mathrm{g} / \mathrm{kg})$ and ENR $(2.0-160.9 \mu \mathrm{g} / \mathrm{kg})$ in swine muscle tissues.

\subsubsection{SAs}

The concentrations of SAs in mollusks from Bohai Sea were lower than those of QNs. The levels of sulfonamides ranged from BDL to $69.50 \mu \mathrm{g} / \mathrm{kg}$ (Sca, Shouguang) in the 2006 samples, from BDL to $76.75 \mu \mathrm{g} / \mathrm{kg}$ (Nev, Beidaihe) in the 2007 samples, and from BDL to $14.41 \mu \mathrm{g} / \mathrm{kg}$ (Myt, Dalian) in the 2009 samples. Furthermore, the $\sum$ SAs concentrations in mollusks in the Bohai Sea were all lower than the maximum residue limits of $100 \mu \mathrm{g} / \mathrm{kg}$, according to European Commission, Council Regulation (EU) No 37/2010 (EU, 2009).

The concentrations of SAs were in the order of "SMM > ST $>$ SMX $>$ SIA $>$ SMR $>$ SPD $>$ SDMD $>$ SDZ $>$ SDM", and the first four sulfonamides in mollusks accounted for $81.2 \%$ of $\sum$ SAs. SMM possessed the highest mean concentration of $1.6 \mu \mathrm{g} / \mathrm{kg}$, followed by ST, SMX and SIA, with mean concentrations of 1.33, 1.01, and $0.91 \mu \mathrm{g} / \mathrm{kg}$, respectively. The mean concentrations of SMR and SPD were only 0.42 and $0.26 \mu \mathrm{g} / \mathrm{kg}$, respectively, although they were frequently detected in samples. The last three SAs were not frequently detected, and their mean concentrations were below $0.20 \mu \mathrm{g} / \mathrm{kg}$.
SAs had been found previously in mollusks in this region. $\mathrm{Na}$ et al. (2009) reported high concentration of SDZ in Mac C of Dalian in China (6.5-143.3 $\mu \mathrm{g} / \mathrm{kg}$ ), but no detectable SMM and SMX. However, similar concentrations of SAs (SMR, 0.35-0.39 $\mu \mathrm{g} / \mathrm{kg}, \mathrm{SD}$, $0.32-0.78 \mu \mathrm{g} / \mathrm{kg}, \mathrm{SMX}, 0.95 \mu \mathrm{g} / \mathrm{kg}$ ) as those in the present study in hake tissues and mussels (Myt) were detected in Spain (FernandezTorres et al., 2010). Compared to other foodstuffs, the concentrations of SAs in mollusks from the Bohai Sea were lower. Higher concentration of SDMD (1.1-43.2 $\mu \mathrm{g} / \mathrm{kg})$ and SDZ $(2.0-160.9 \mu \mathrm{g} / \mathrm{kg})$ in swine muscle tissues was reported in Spain (Chico et al., 2008), and higher level of SDZ ( $83 \mu \mathrm{g} / \mathrm{kg})$ in bovine muscle tissues was also detected in Spain (Carretero et al., 2008).

\subsection{3. $M C S$}

MCs were only detected in a few mollusks with detection rates of between 1 and 65\%. The concentration of $\sum M C s$ ranged from BDL to $26.30 \mu \mathrm{g} / \mathrm{kg}$ (Nev, Beidaihe) in the 2006 samples, from BDL to $31.61 \mu \mathrm{g} / \mathrm{kg}$ (Mac C, Yingkou) in the 2007 samples, and from BDL to $28.55 \mu \mathrm{g} / \mathrm{kg}$ (Rap, Huludao) in the 2009 samples.

The concentrations of MCs were in the order of "ERY $>$ SPI $>$ ROX $>$ JOS $>$ TYL". The major macrolides in mollusks were ERY, which had mean concentration of $1.65 \mu \mathrm{g} / \mathrm{kg}$ and accounted for $64.0 \%$ of $\sum M C s$. This is consistent with the fact that ERY is the most commonly used MCs in Bohai Bay. The concentration of SPI was the second highest with $1.65 \mu \mathrm{g} / \mathrm{kg}$ of mean level. ROX and JOS were only found in a few samples with 24 and $7 \%$ of detection rates, respectively. In addition, TYL was not detected in any sample.

Data on MCs in mollusks were also limited all over the world and information on other food was available. Similar concentration of ERY $(3.2 \mu \mathrm{g} / \mathrm{kg})$ and TYL $(2.4 \mu \mathrm{g} / \mathrm{kg})$ in bovine muscle tissues was reported in Spain (Juan et al., 2010), while higher concentration of ERY $(8.6 \mu \mathrm{g} / \mathrm{kg})$ and TYL $(2.0-160.9 \mu \mathrm{g} / \mathrm{kg})$ in swine muscle tissues were found in Spain (Vidal et al., 2009).

Up to now, limited data on the accumulation of antibiotics in mollusks is available. In recent study it was reported that the mean concentrations of individual QNs, SAs and MCs in Bohai Sea water were in the range of $110-460,17-37$ and $30-113 \mathrm{ng} / \mathrm{L}$, respectively (Zou et al., 2011). We roughly analyzed the potential accumulation of antibiotics based on this data, indicating that most selected antibiotics may be slightly accumulated in the mollusks.

\subsection{Annual variation of antibiotics}

Box-and-whisker plots are shown in Fig. 2 to visualize the distribution of antibiotics in mollusks. No significant variation was found for the concentrations of $\sum \mathrm{QNs}$, $\sum$ SAs and $\sum \mathrm{MCs}$ among the three years (Fig. 2a). The results of analysis of variance (one-way ANOVA) for QNs, SAs and MCs are listed in Table 2. The levels of QNs and MCs in this region were both not significantly different from year to year $(p>0.05)$. However, the concentrations of SAs showed obvious variation between 2006 and $2009(p<0.05)$. As shown in Table 2, the mean concentrations of SAs in 2006 were twice higher than those in 2009, indicating that SAs pollution in Bohai Sea slowed down in the three years. This improvement may have been

Table 2

One-Way ANOVA for the concentrations of QNs, SAs and MCs in mollusks in three years.

\begin{tabular}{llll}
\hline & $p$ & & \\
\cline { 2 - 4 } & 2006 vs 2007 & 2006 vs 2009 & 2007 vs 2009 \\
\hline$\sum$ QNs & 0.965 & 0.063 & 0.482 \\
$\sum$ SAs & 0.394 & $0.041^{\mathrm{a}}$ & 0.376 \\
$\sum$ MCs & 0.467 & 0.151 & 0.941 \\
\hline
\end{tabular}

a Mean difference is significant at the 0.05 level. 

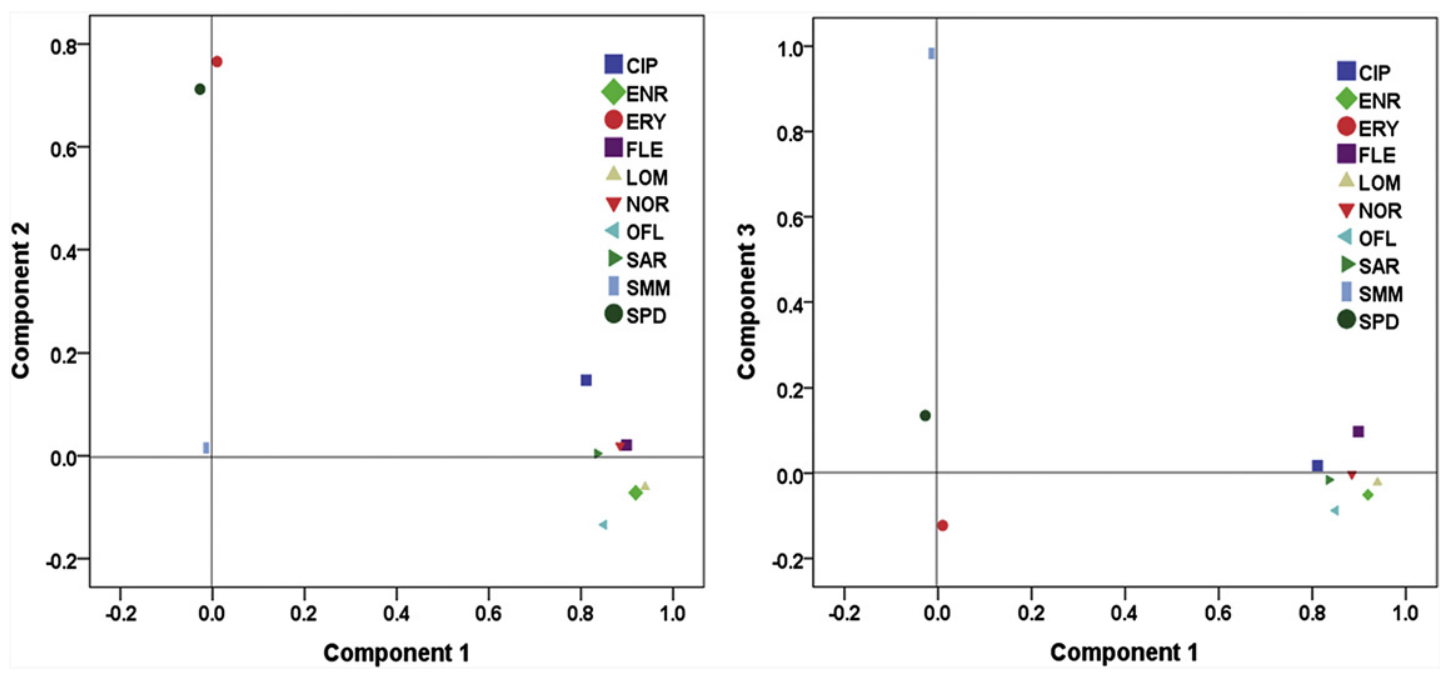

Fig. 3. The loading plots of PCA by the database of antibiotics in mollusks collected from the Chinese Bohai Sea in 2006,2007 and 2009.

caused by the prohibition of some SAs as feed additive for particular fish species, according to the Use Standard of Pollution-Free Food and Fish that was printed and issued by the Ministry of Agriculture in 2002.

\subsection{Comparison of sampling sites}

No significant differences were observed for $\Sigma$ SAs in mollusks among the nine sampling sites (Fig. S1a). However, higher residue levels of $\Sigma$ QNs were detected in Dalian (mean $181.64 \mu \mathrm{g} / \mathrm{kg}$ ), while these levels were much lower in Beidaihe (mean, $50.73 \mu \mathrm{g} / \mathrm{kg}$ ) and Yingkou (mean, $56.48 \mu \mathrm{g} / \mathrm{kg}$ ). Furthermore, higher concentrations of $\Sigma$ MCs (mean, $4.11 \mu \mathrm{g} / \mathrm{kg}$ ) were detected in Beidaihe, while they were low in Dalian (mean, $0.85 \mu \mathrm{g} / \mathrm{kg}$ ). In general, the result showed that the pollution was antibiotics species dependent and widespread in this area with high population density.

PCA was performed to analyze the residual antibiotics with detectable rates of over $60 \%$, which included seven QNs, two SAs, and one MC. The varimax rotation reduced all variables to three different PCs, which represent $75.58 \%$ of the total variance. According to these rules, loadings is situated closely in bitplots represent the variables that are highly correlated. Therefore, PCA was used to identify the correlation between various parameters of pollutants. As shown in Fig. 3, PC1 accounted for 53.96\% of the total variance and had strong positive loadings on seven QNs; PC2 accounted for as much as $11.43 \%$ of the total variance and had moderately positive loadings for ERY and SPD; PC3 accounted for $10.20 \%$ of the total variance and had high correlation with SMM.

Dalian had higher loading values of PC1 in the component plot (Fig. 4), indicating that residual QNs were the main antibiotic pollutant of Dalian, which is one of the largest seaports in China. In addition, Beidaihe was highly polluted by ERY and SPD, and Huludao was severely contaminated by SMM (Fig. 4).

\subsection{Comparison of mollusks species}

No significant differences in $\Sigma M C s$ concentrations were observed among different species of mollusks (Fig. S2a). However, relatively high residue levels of $\Sigma$ QNs were detected in Mac V (mean $128.87 \mu \mathrm{g} / \mathrm{kg}$ ) and Mer (mean $128.19 \mu \mathrm{g} / \mathrm{kg}$ ), while low residue levels of $\Sigma Q N s$ were detected in Mya (mean $43.32 \mu \mathrm{g} / \mathrm{kg}$ ) and Amu (mean $51.87 \mu \mathrm{g} / \mathrm{kg}$ ). In addition, significantly higher levels
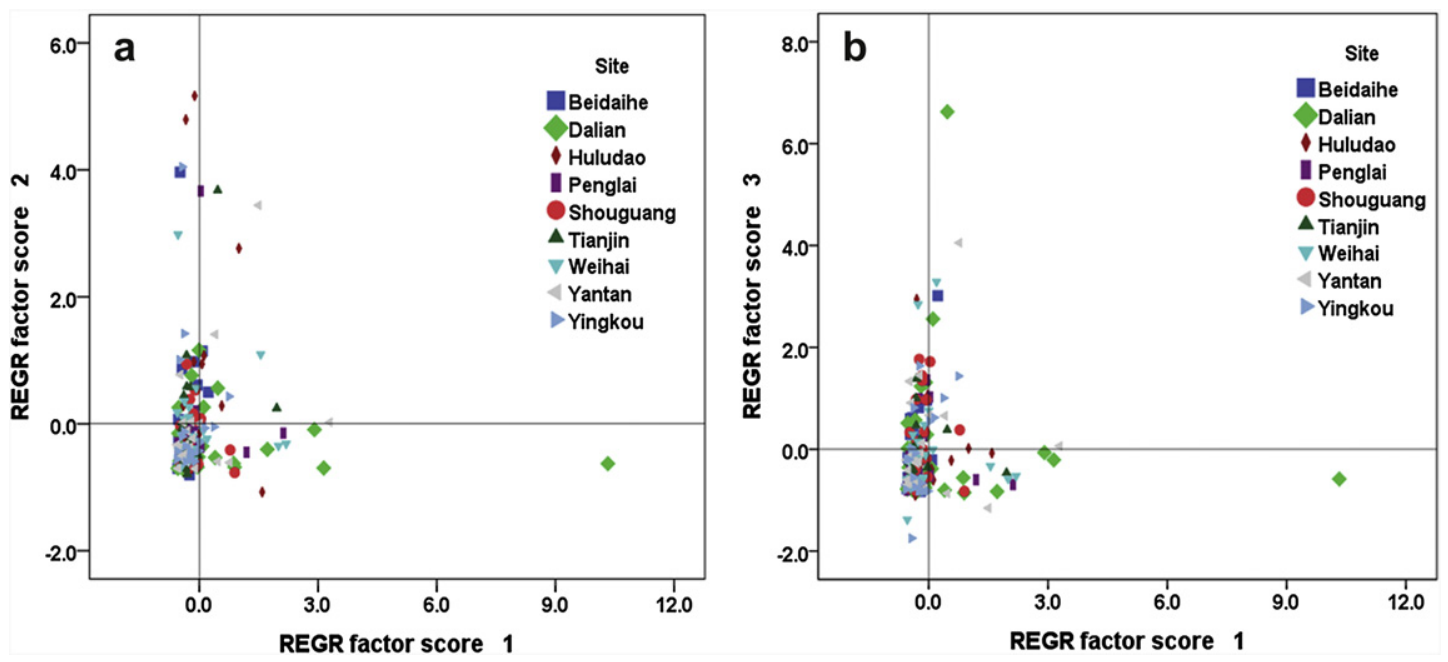

Fig. 4. The score plots of PCA by the database of antibiotics in mollusks collected from nine coastal cities along the Bohai Sea. a: PC1 vs PC2; b: PC1 vs PC3. 

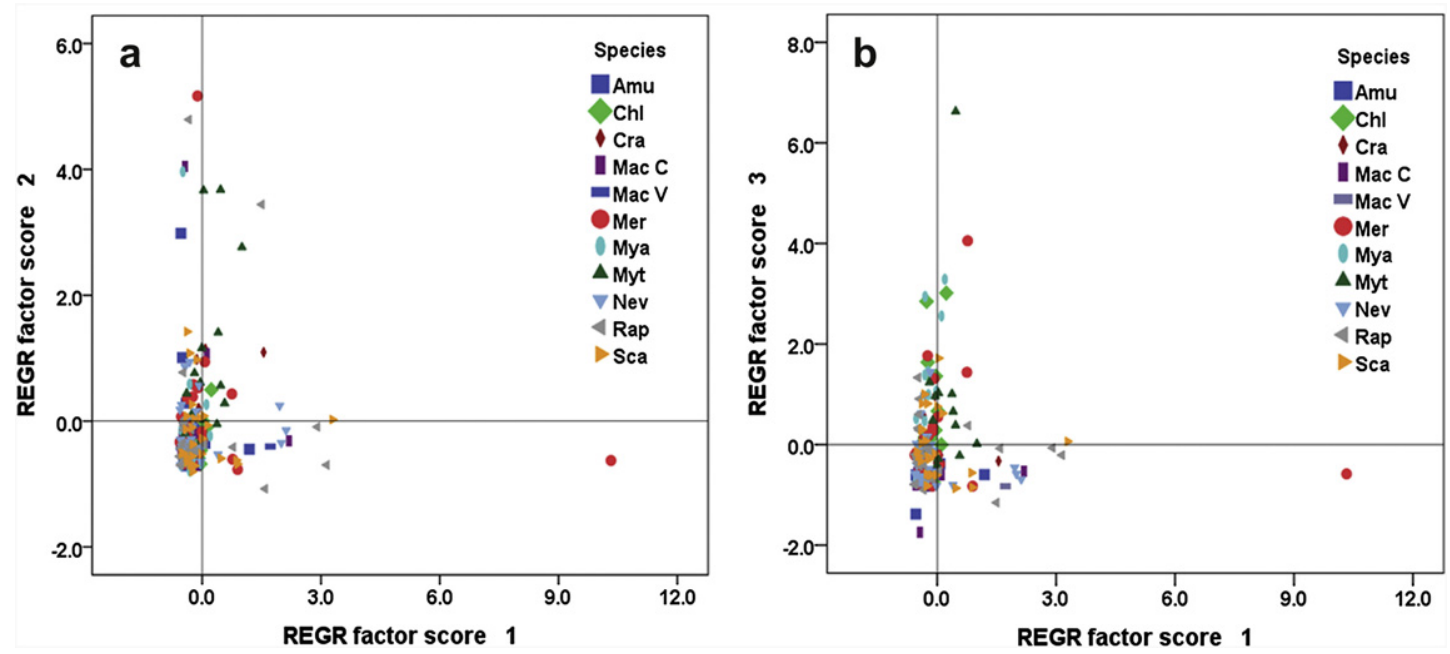

Fig. 5. The score plots of PCA by the database of antibiotics in eleven kinds of mollusks collected from the coastal water of the Bohai Sea. a: PC1 vs PC2; b: PC1 vs PC3.

of SAs were observed in Myt (mean $9.60 \mu \mathrm{g} / \mathrm{kg}$ ) and Sca (mean $9.51 \mu \mathrm{g} / \mathrm{kg}$ ) than those in Mac C (mean $1.77 \mu \mathrm{g} / \mathrm{kg}$ ) and Rap (mean $2.93 \mu \mathrm{g} / \mathrm{kg})$.

PCA was also applied to determine the characters of pollutants in different mollusks species. Mac V and Mer had higher loading values of PC1 and PC3 in the component plot (Fig. 5), indicating that the concentrations of QNs and SMM in these samples were relatively higher; and Myt had higher loading values of PC2, indicating much higher concentrations of ERY and SPD than other species.

\subsection{Risk assessment for the seafood}

Mollusks are one of the most popular seafoods in China, especially for those who live in coastal cities. Therefore, it is necessary to evaluate whether dietary intake of mollusks containing antibiotics is harmful to public health. Indeed, the EU has set MRLs for some residual antibiotics in foods of animal origin to protect public health, based on related scientific assessments (Table S6). In the present study, 15 out of 190 samples exceeded the MRL of SAR $(30 \mu \mathrm{g} / \mathrm{kg})$ for muscle of Salmonidae, and 5 of the 15 samples were from Dalian. As for ENR (Sum of enrofloxacin and ciprofloxacin), 8 out of 190 samples were above the MRL $(100 \mu \mathrm{g} / \mathrm{kg}), 3$ of which were from Dalian. Therefore, it is reasonable to advise that consumption of mollusks in the Bohai Sea may pose potential health risks to local residents. In addition, Dalian should have extra attention than other areas, because it may have the highest antibiotic contaminations in mollusks.

\section{Conclusion}

In this study, the levels of residue antibiotics were investigated for various mollusks that were collected from nine coastal cities along the Chinese Bohai Sea. QNs were widely distributed in mollusks in this area. However, no significant changes were observed in the concentrations of QNs and MCs from 2006 to 2007 and to 2009, while those of SAs were reduced in this period of time. Furthermore, the levels of QNs were higher in Mac V and Mer than that in other species, indicating that these two species can be used to evaluate the contamination of QNs in the Bohai coastal areas.

\section{Acknowledgments}

This work was supported by the National Natural Science Foundation of China (No. 20837003 and 20890111) and the National Basic Research Program of China (2009CB421605).

\section{Appendix. Supplementary material}

Supplementary material associated with this article can be found, in the online version, at doi:10.1016/j.envpol.2011.10.022.

\section{References}

Arikan, O.A., Rice, C., Codling, E., 2008. Occurrence of antibiotics and hormones in a major agricultural watershed. Desalination 226, 121-133.

Canada-Canada, F., Munoz de la Pena, A., Espinosa-Mansilla, A., 2009. Analysis of antibiotics in fish samples. Analytical and Bioanalytical Chemistry 395 987-1008.

Carretero, V., Blasco, C., Pico, Y., 2008. Multi-class determination of antimicrobials in meat by pressurized liquid extraction and liquid chromatography-tandem mass spectrometry. Journal of Chromatography A 1209, 162-173.

Chico, J., Rubies, A., Centrich, F., Companyo, R., Prat, M.D., Granados, M., 2008. Highthroughput multiclass method for antibiotic residue analysis by liquid chromatography-tandem mass spectrometry. Journal of Chromatography A $1213,189-199$.

Cruz Moreno-Bondi, M., Dolores Marazuela, M., Herranz, S., Rodriguez, E., 2009. An overview of sample preparation procedures for LC-MS multiclass antibiotic determination in environmental and food samples. Analytical and Bioanalytical Chemistry 395, 921-946.

Cunningham, V.L., Binks, S.P., Olson, M.J., 2009. Human health risk assessment from the presence of human pharmaceuticals in the aquatic environment. Regulatory Toxicology and Pharmacology 53, 39-45.

Díaz-Cruz, M.S., García-Galán, M.J., Guerra, P., Jelic, A., Postigo, C., Eljarrat, E., Farré, M., López de Alda, M.J., Petrovic, M., Barceló, D., 2009. Analysis of selected emerging contaminants in sewage sludge. TRAC Trends in Analytical Chemistry 28, 1263-1275.

EPA, 2007. Method 1694: Pharmaceuticals and Personal Care Products in Water, Soil, Sediment, and Biosolids by HPLC/MS/MS. http://www.caslab.com/EPAMethods/PDF/1694.pdf.

EU (European Union), 2009. Regulations on Pharmacologically Active Substances and Their Classification Regarding Maximum Residue Limits in Foodstuffs of Animal Origin. http://ec.europa.eu/health/files/eudralex/vol-5/reg_2010_37/ reg_2010_37_en.pdf.

Fernandez-Torres, R., Lopez, M.A.B., Consentino, M.O., Mochon, M.C., PerezBernal, J.L., 2010. Application of enzymatic probe sonication extraction for the determination of selected veterinary antibiotics and their main metabolites in fish and mussel samples. Analytica Chimica Acta 675, 156-164.

Golet, E.M., Strehler, A., Alder, A.C., Giger, W., 2002. Determination of fluoroquinolone antibacterial agents in sewage sludge and sludge-treated soil using accelerated solvent extraction followed by solid-phase extraction. Analytical Chemistry 74, 5455-5462. 
Hu, X.G., Zhou, Q.X., Luo, Y., 2010. Occurrence and source analysis of typical veterinary antibiotics in manure, soil, vegetables and groundwater from organic vegetable bases, northern China. Environmental Pollution 158, 2992-2998.

Juan-Garcia, A., Font, G., Pico, Y., 2006. Determination of quinolone residues in chicken and fish by capillary electrophoresis-mass spectrometry. Electrophoresis 27, 2240-2249.

Juan-Garcia, A., Font, G., Pico, Y., 2007. Simultaneous determination of different classes of antibiotics in fish and livestock by CE-MS. Electrophoresis 28, 4180-4191.

Juan, C., Molto, J.C., Manes, J., Font, G., 2010. Determination of macrolide and lincosamide antibiotics by pressurised liquid extraction and liquid chromatographytandem mass spectrometry in meat and milk. Food Control 21, 1703-1709.

Kümmerer, K., 2009. Antibiotics in the aquatic environment-A review-Part I. Chemosphere 75, 417-434.

Liang, L.N., Shi, J.B., He, B., Jiang, G.B., Yuan, C.G., 2003. Investigation of methylmercury and total mercury contamination in mollusk samples collected from coastal sites along the Chinese Bohai Sea. Journal of Agricultural and Food Chemistry 51, 7373-7378.

Luo, Y., Mao, D., Rysz, M., Zhou, Q., Zhang, H., Xu, L., Alvarez, P.J.J., 2010. Trends in antibiotic resistance genes occurrence in the Haihe River, China. Environmental Science \& Technology 44, 7220-7225.

Massey, L.B., Haggard, B.E., Galloway, J.M., Loftin, K.A., Meyer, M.T., Green, W.R., 2010. Antibiotic fate and transport in three effluent-dominated Ozark streams. Ecological Engineering 36, 930-938.

Na, G.S., Zhou, C.G., Wang, Z., Wang, Q., Li, H.X., Chen, T., Zhang, Y.M., Yao, Z.W., 2009. Simultaneous determination of Fifteen sulfonamide residues in Macrobenthos by high-Performance liquid chromatography tandem mass spectrometry. Research of Environmental Sciences 22, 434-437.

Nie, X.p., He, X.t., Yang, Y.t., Chen, K.c., Pan, D.b., 2009. Investigation of quinolones in aquaculture environment of the Pearl River Delta. Environmental Science 30, 266-270.

Pan, Y., Shi, Y., Wang, Y., Cai, Y., Jiang, G., 2010. Investigation of perfluorinated compounds (PFCs) in mollusks from coastal waters in the Bohai Sea of China. Journal of Environmental Monitoring 12, 508-513.

Sapkota, A., Sapkota, A.R., Kucharski, M., Burke, J., McKenzie, S., Walker, P., Lawrence, R., 2008. Aquaculture practices and potential human health risks: current knowledge and future priorities. Environment International 34,1215-1226.

Tamtam, F., van Oort, F., Le Bot, B., Dinh, T., Mompelat, S., Chevreuil, M., Lamy, I., Thiry, M., 2011. Assessing the fate of antibiotic contaminants in metal contaminated soils four years after cessation of long-term waste water irrigation. Science of the Total Environment 409, 540-547.
Ternes, T.A., Bonerz, M., Herrmann, N., Teiser, B., Andersen, H.R., 2007. Irrigation of treated wastewater in Braunschweig, Germany: an option to remove pharmaceuticals and musk fragrances. Chemosphere 66, 894-904.

Vidal, J.L.M., Aguilera-Luiz, M.D., Romero-Gonzalez, R., Frenich, A.G., 2009. Multiclass analysis of antibiotic residues in Honey by Ultraperformance liquid chromatography-tandem mass spectrometry. Journal of Agricultural and Food Chemistry 57, 1760-1767.

Wang, J., 2009. Analysis of macrolide antibiotics, using liquid chromatography-mass spectrometry, in food, biological and environmental matrices. Mass Spectrometry Reviews 28, 50-92.

Wang, Y.W., Wang, T.H., Li, A., Fu, J.J., Wang, P., Zhang, Q.H., Jiang, G.B., 2008 Selection of bioindicators of polybrominated diphenyl ethers, polychlorinated biphenyls, and organochlorine pesticides in mollusks in the Chinese Bohai Sea. Environmental Science \& Technology 42, 7159-7165.

Wang, Y.W., Yang, R.Q., Jiang, G.B., 2007. Investigation of organochlorine pesticides (OCPs) in mollusks collected from coastal sites along the Chinese Bohai Sea from 2002 to 2004. Environmental Pollution 146, 100-106.

Wiechula, D., Fischer, A., Kwapulinski, J., Loska, K., Fischer, T., Kurpas, P., 2006 Multivariate statistical analysis of metal concentrations in teeth of residents of Silesian region, southern Poland. Archives of Environmental Contamination and Toxicology 51, 314-320.

Xie, D.H., Yu, X.J., Yin, J.Y., Ni, M.L., 2008. Study on multi-residues determ ination of fluoroquinolones in roast eels. Chinese Journal of Health Laboratory Technology 18, 969-971.

Yang, R.Q., Cao, D.D., Zhou, Q.F., Wang, Y.W., Jiang, G.B., 2008. Distribution and temporal trends of butyltins monitored by molluscs along the Chinese Bohai coast from 2002 to 2005. Environment International 34, 804-810.

Ye, Z., Weinberg, H.S., Meyer, M.T., 2007. Trace analysis of Trimethoprim and sulfonamide, macrolide, quinolone, and Tetracycline antibiotics in Chlorinated Drinking water using liquid chromatography electrospray tandem mass spectrometry. Analytical Chemistry 79, 1135-1144.

Zhang, P., Song, J., Yuan, H., 2009. Persistent organic pollutant residues in the sediments and mollusks from the Bohai Sea coastal areas, North China: an overview. Environment International 35, 632-646.

Zhao, S.J., Jiang, H.Y., Li, X.L., Mi, T.J., Li, C., Shen, J.Z., 2007. Simultaneous determination of trace levels of 10 quinolones in swine, chicken, and shrimp muscle tissues using HPLC with programmable fluorescence detection. Journal of Agricultural and Food Chemistry 55, 3829-3834.

Zou, S., Xu, W., Zhang, R., Tang, J., Chen, Y., Zhang, G., 2011. Occurrence and distribution of antibiotics in coastal water of the Bohai Bay, China: impacts of river discharge and aquaculture activities. Environmental Pollution 159, 2913-2920. 